52. Thomas JW, Ashcraft MLF. Measuring severity of illness: six severity systems and their ability to explain cost variations. Inquiry 1991;28:39-55.

53. Patient classification systems: an evaluation of the state of the art. Vol 1. Case Mix Research. Kingston, Ontario, Canada: Queen's University; 1991.

54. Iezzoni LI, Hotchkin EK, Ash AS, Schwartz M, Mackiernan Y. MedisGroups databases: the impact of data collection guidelines on predicting in-hospital mortality. Med Care 1993;31:277-283.
55. Hayward RA, McMahon LF, Bernard AM. Evaluating the care of general medicine inpatients: how good is implicit review? Ann Intern Med 1993;118:550-556.

56. Wennberg JE. Future directions for small area variations. Med Care 1993;31:YS75-YS80.

57. McMahon LF, Newbold R. Variation in resource use within diagnosis-related groups: the effect of severity of illness and physician practice. Med Care 1986;24:388-397.

\title{
Computer Reminders Did Not Improve Inpatient Preventive Care
}

\section{Gina Pugliese, RN, MS Martin S. Favero, PhD}

For outpatients, computer-generated reminders for preventive care have been shown to be uniformly effective. To determine the extent to which computer reminders can increase the provision of inpatient preventive care, researchers at Indiana University School of Medicine conducted a randomized controlled trial involving 78 house staff rotating on six general medicine services. The physicians received reminders printed on daily rounds reports about preventive care for which their patients were eligible, and suggested orders for preventive care in the electronic patient record were accessed by physicians through data retrieval terminals and orderentry workstations located throughout the hospital. Six of the 22 preventive care recommendations and indications were related to prevention of infection, such as hepatitis B testing or immunization and pneumococcal vaccination.

No significant differences were found between intervention and control physicians in compliance with preventive care guidelines in the aggregate or when individual preventive care actions were analyzed. This was true even though most physicians endorsed providing most kinds of preventive care for hospitalized patients. The authors conclude that more intensive intervention or more direct linkages between inpatient and outpatient care providers may be required to overcome this resistance. The authors suggest an alternative approach might be to establish selected preventive care measures that would be considered "standing orders" to be undertaken unless the physician explicitly countermands them. This has proven to be effective in increasing influenza vaccination rates for high-risk inpatients from $25 \%$ to $70 \%$, by allowing nurses to administer the vaccine without a physician order.

FROM: Overhage JM, Tierney WM, McDonald CJ. Computer reminders to implement preventive guidelines for hospitalized patients. Arch Intern Med 1996;156:1551-1556. 